\title{
Simulation of Accidental Shutdowns of Thermal Equipment for Artificial Aging Treatment and Their Effect on the Mechanical Properties of 6061 Aluminium Alloy Plates
}

\author{
Maria STOICANESCU \\ Transilvania University of Brasov, Romania, stoican.m@unitbv.ro \\ Gheorghe POPA \\ ALRO SA, Romania, gpopa@alro.ro \\ Marin PETRE \\ ALRO SA, Romania, mapetre@alro.ro \\ Nicuşor Constantin DRĂGHICI \\ ALRO SA, Romania, cdraghici@alro.ro
}

\begin{abstract}
A study on the effects of accidental shutdowns of thermal equipment for artificial aging treatment on the mechanical properties of hot rolled thick plate products of $6 \mathrm{xxx}$ alloys was performed. The present study was initiated by performing tests and simulations in the laboratory and continued with the validation in industrial regime on concrete situations of the obtained results. All tests were performed on 6061 aluminium alloy plates, T651 temper. The present study aimed to provide solutions for capitalization, without negative consequences on the quality, of thick plate products made of aluminium alloys, in special cases of accidental shutdown of thermal equipment related to the artificial treatment of artificial aging. A series of solutions are presented for taking the best decision in such possible unwanted situations.
\end{abstract}

\section{Keywords}

aluminium alloy 6061, mechanical properties, artificial aging, T651 temper

\section{Introduction}

Aluminium is very light and is highly attracted by modern manufacturing technologies. It is reported that worldwide $90 \%$ aluminium alloys pipes and tubes are manufactured from 6xxx aluminium alloy [1]. This type of aluminium alloy is heat treatable and contains Si and Mg as a major alloying element.

Age hardening treatment includes two major steps: solution treatment and artificial aging. Solution treatment involves heating of materials around its critical temperatures, soaking for a certain time and rapid quenching. Quenching is carried out to keep the dissolved constituents in solid solution $[2,3]$. While, artificial aging treatment means re-heating of the solution treated samples in the range of 175$420^{\circ} \mathrm{C}$ for various time periods for precipitation of the secondary phase [4].

In this work, the experiments were performed on 6061 aluminium alloy plate, T651 temper. An important factor in obtaining the desired quality for the plates subjected to heat treatment is the control of the heating of the material to achieve the required mechanical properties [5].

Considering the stages of carrying out a cycle of artificial aging heat treatment to obtain the state T651 in the hardenable aluminium alloys (heating and holding time), in the case of laboratory heat treatment simulations were identified two possible cases of accidental interruptions of heat treatments due to certain defects in the operation of the equipment, respectively, during the heating or the holding time.

In addition to the stage in the cycle (heating or holding) in which accidental shutdowns of thermal equipment may occur, another important factor in determining the degree of impact on mechanical properties is the duration of these breaks in the heat treatment cycles.

The present study aimed to prevent unwanted situations that may occur in the normal operation of the thermal equipment, and to find solutions for capitalizing on the treated material. 


\section{Experimental}

In order to perform simulations of artificial aging heat treatments in the laboratory, a representative thickness $(50.8 \mathrm{~mm})$ of 6061 aluminium alloy plates was selected, from which samples were taken after the industrial quenching. The 6061 aluminium alloy plates were obtained from a cast slab with the chemical composition according to the Table 1.

Table 1. Chemical composition of 6061 aluminium alloy plates used in the experiments (mass fraction, \%)

\begin{tabular}{|c|c|c|c|c|c|c|c|c|c|c|}
\hline \multirow{2}{*}{$\mathrm{Si}$} & \multirow{2}{*}{$\mathrm{Fe}$} & \multirow{2}{*}{$\mathrm{Cu}$} & \multirow{2}{*}{$\mathrm{Mn}$} & \multirow{2}{*}{$\mathrm{Mg}$} & \multirow{2}{*}{$\mathrm{Cr}$} & \multirow{2}{*}{$\mathrm{Zn}$} & \multirow{2}{*}{$\mathrm{Ti}$} & \multicolumn{2}{|c|}{ Other Elements } & \multirow{2}{*}{$\mathrm{Al}$} \\
\hline & & & & & & & & Each & Total & \\
\hline 0.79 & 0.42 & 0.32 & 0.10 & 1.04 & 0.17 & 0.09 & 0.01 & $\leq 0.05$ & $\leq 0.15$ & 96.99 \\
\hline
\end{tabular}

According to the EN 485-2:2016 standard [6], for obtaining the T651 temper for 6061 aluminium alloy plates, after applying the solution heat treatment and quenching, followed by stretching, the plates are subjected to the artificial aging treatment at parameters $177^{\circ} \mathrm{C}$ for $8 \mathrm{~h}$.

To perform the simulations in the laboratory, six cycles were established for the artificial aging heat treatment, according to the Table 2 .

Table 2. Heat treatment cycle parameters that were used in the simulations

\begin{tabular}{|c|c|c|c|}
\hline \multirow{2}{*}{$\begin{array}{c}\text { Cycle } \\
\text { number }\end{array}$} & Heating & \multicolumn{2}{|c|}{ Holding } \\
\cline { 2 - 4 } & Break $[\mathrm{h}]$ & Break $[\mathrm{h}]$ & Holding Time $[\mathrm{h}]$ \\
\hline 1 & - & - & 8 \\
\hline 2 & 1 & - & 8 \\
\hline 3 & - & 1 & 8 \\
\hline 4 & - & 2 & 8 \\
\hline 5 & - & 1 & 7 \\
\hline 6 & - & 2 & 6 \\
\hline
\end{tabular}

The six artificial aging heat treatments are represented graphically in Figure 1.

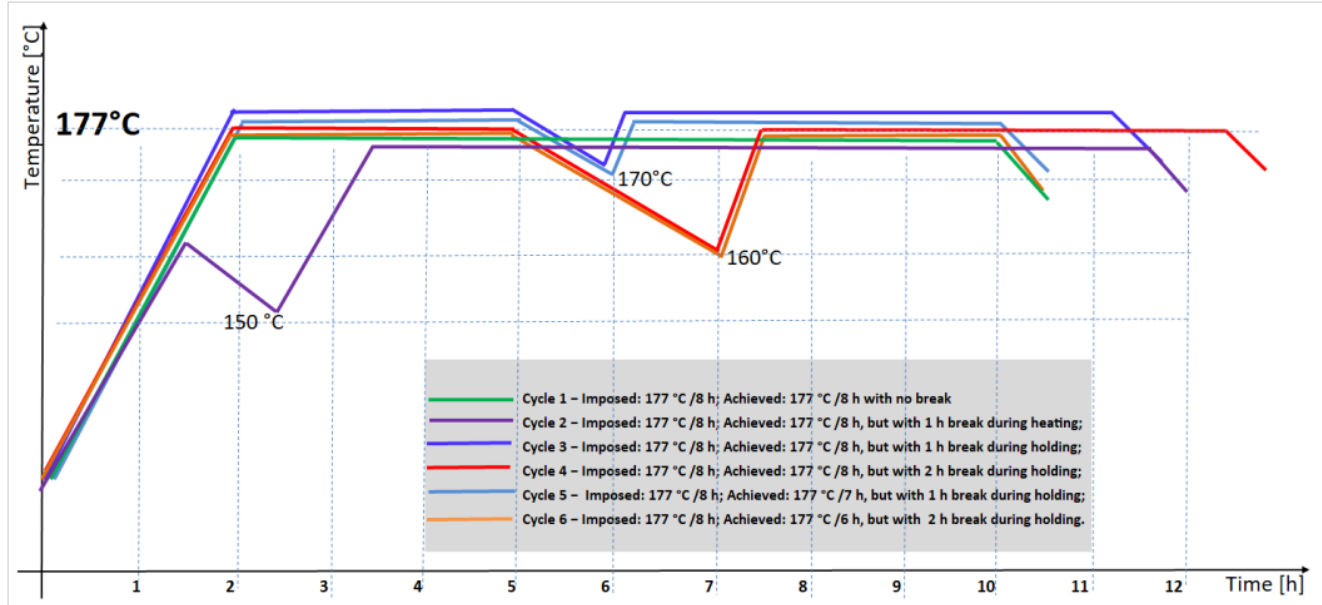

Fig. 1. Schematic representation of the 6 cycles of heat treatment simulated in the laboratory

In establishing the simulation parameters, the normal operation cycle (cycle 1) was taken into account, as well as the accidental shutdowns during the heating period, as well as during the holding period. Breaks of $1 \mathrm{~h}$ and $2 \mathrm{~h}$, respectively, were considered for both heating and holding period. In addition, two different cases were considered in operation: the continuation of the cycle without considering as time the accidental shutdown, and respectively the continuation of the cycle with the addition to the duration of the period the time in which the cycle was interrupted. 


\section{Results. Discussion}

After performing the artificial aging heat treatment simulations in the laboratory, the samples taken from the 6061 aluminium alloy plate, with $50.8 \mathrm{~mm}$ thickness, were processed for the tensile tests.

The results of the tensile tests are presented in the Table 3 and graphically in the Figures $2-4$. The mechanical properties, respectively: the ultimate tensile strength $(R m)$, the yield tensile strength $\left(R p_{0.2}\right)$ and the elongation $\left(A_{50 \mathrm{~mm}}\right)$ were determined on the transversal direction.

Table 3. Mechanical properties of 6061 aluminium alloy samples for the six simulations performed in the laboratory

\begin{tabular}{|c|c|c|c|c|c|c|}
\hline \multirow{2}{*}{$\begin{array}{c}\text { Cycle } \\
\text { number }\end{array}$} & Heating & \multicolumn{3}{|c|}{ Holding } & \multicolumn{3}{c|}{ Mechanical Property } \\
\cline { 2 - 7 } & Break $[\mathrm{h}]$ & \multicolumn{1}{|c|}{ Break $[\mathrm{h}]$} & Holding Time $[\mathrm{h}]$ & $R m[\mathrm{MPa}]$ & $R p_{0.2}[\mathrm{MPa}]$ & $A_{50 \mathrm{~mm}}[\%]$ \\
\hline \multicolumn{2}{|c|}{ Imposed values according EN 485-2 } & 8 & 332 & 287 & 13.5 \\
\hline 1 & - & - & 8 & 331 & 279 & 13.0 \\
\hline 2 & 1 & - & 8 & 329 & 267 & 17.5 \\
\hline 3 & - & 1 & 8 & 324 & 272 & 15.5 \\
\hline 4 & - & 2 & 7 & 320 & 266 & 11.0 \\
\hline 5 & - & 1 & 6 & 313 & $\mathbf{2 3 3}$ & 19.0 \\
\hline 6 & - & 2 & & & & \\
\hline
\end{tabular}

In general, for $R m$ and $R p_{0.2}$ a decreasing trend was recorded, and for $A_{50 \mathrm{~mm}}$ an increasing trend. The maximum values of $R m$ (332 and $331 \mathrm{MPa}$ ) were obtained in the case of the first and second cycle, respectively the reference cycle, without interruption and the cycle in which the interruption took place during the heating period with $1 \mathrm{~h}$.

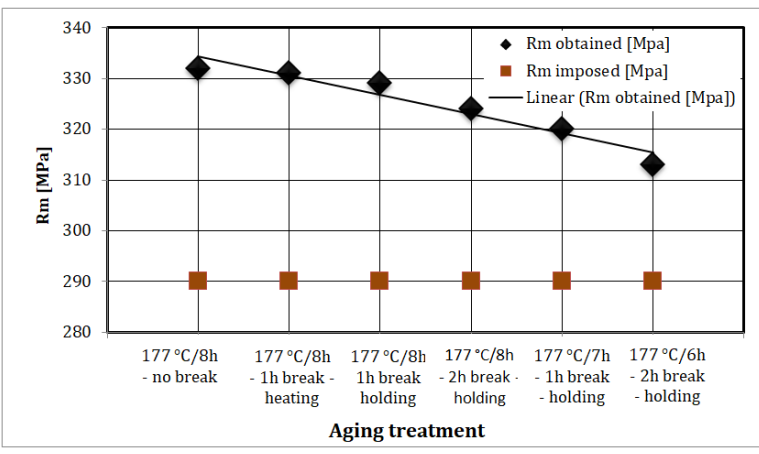

Fig. 2. Evolution of $R m$ depending on the heat treatment cycle

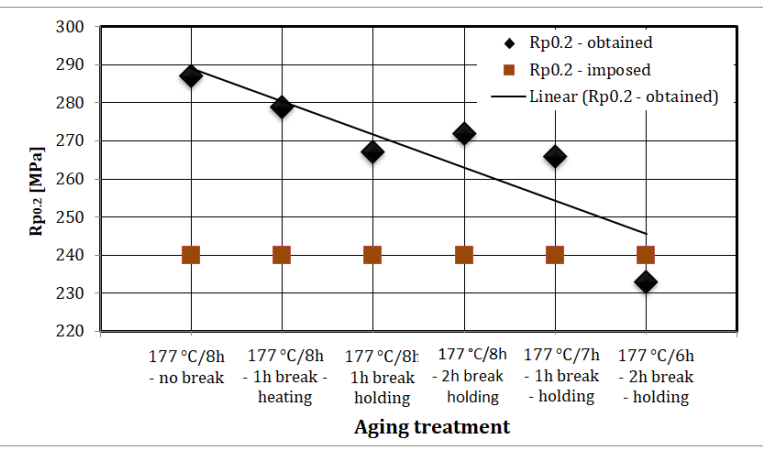

Fig. 3. Evolution of $R p_{0.2}$ depending on the heat treatment cycle

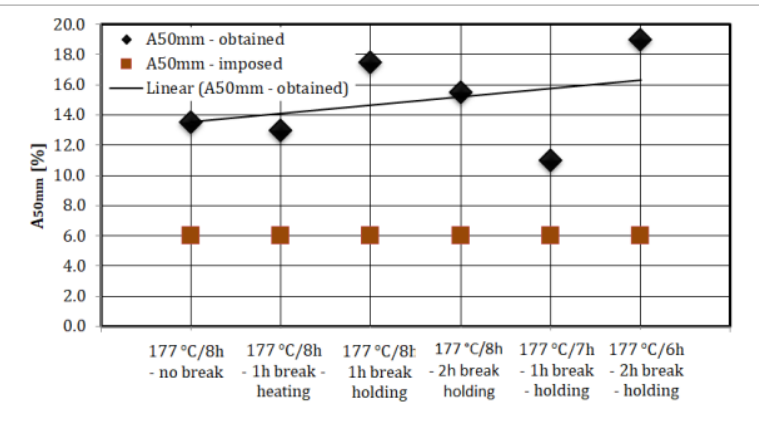

Fig. 4. Evolution of $A_{50 m m}$ depending on the heat treatment cycle

The lowest values for ultimate and yield tensile strength were recorded for the interrupted heat treatment cycle and reduced by 2 hours. Furthermore, the value obtained for yield tensile strength was lower than the value imposed by the standard, respectively $233 \mathrm{MPa}$ compared with $240 \mathrm{MPa}$. 


\section{Industrial Validation of Results of Laboratory Simulations}

A batch-test for the artificial aging heat treatment was performed in the Independent Equipment for the Research of aluminium alloy plates aging process (Figure 5) for validation of the results obtained at the simulations of the aging treatment in the laboratory.

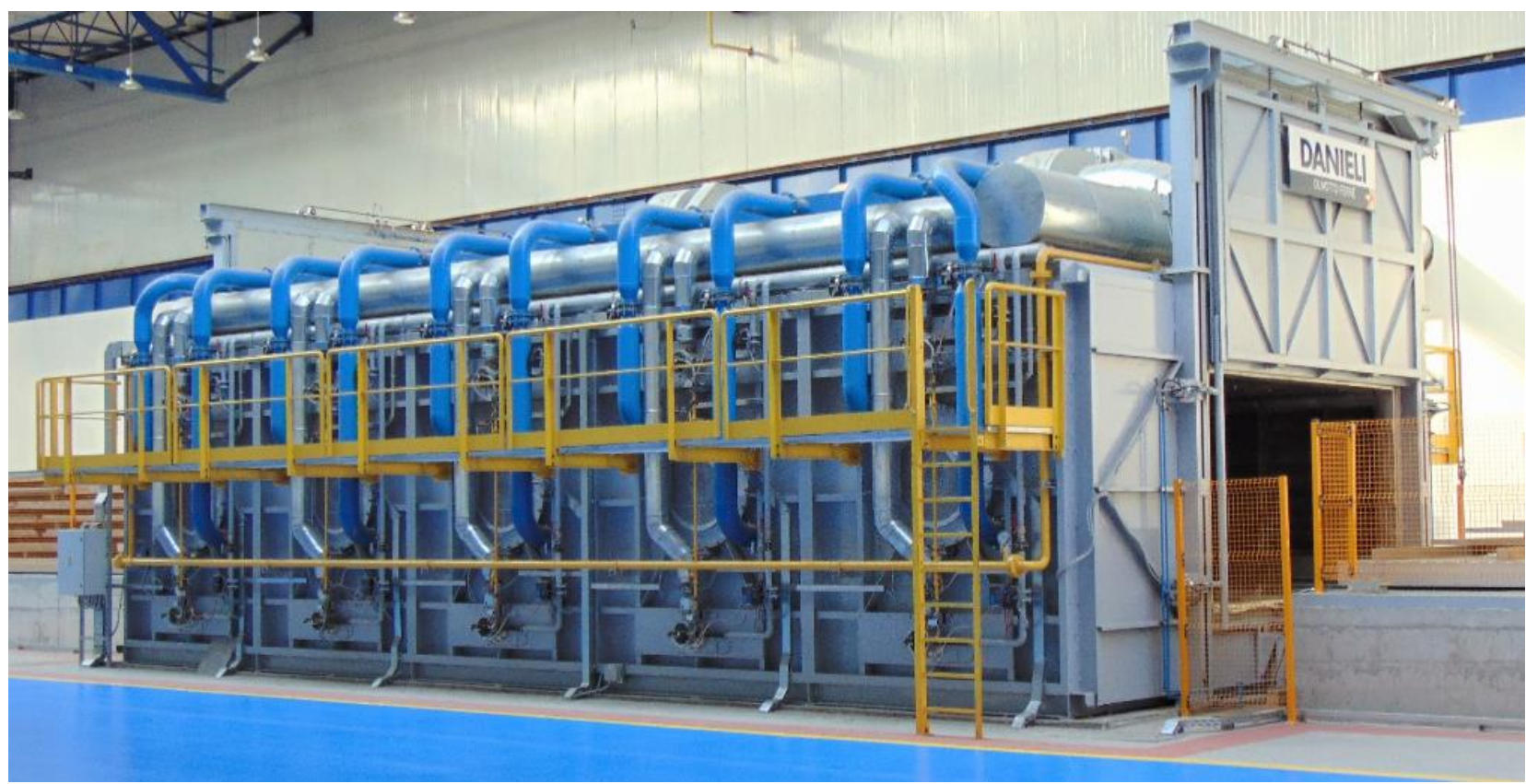

Fig. 5. Danieli batch treatment furnace, aging 70 tons per aluminium plates treatment cycle, provided with the latest technology and commissioned in 2019 year, in the ALRO plant in Romania

In the case-test, the treatment cycle had an "accidental" interruption of 2 hours during the holding period due to a simulated voltage drop at the thermal equipment. As a result of this "process problem" during the "accidental" shutdown period, the temperature of the material thermocouples was not recorded correctly.

The reconstruction of the treatment diagram can be found in Figure 6. The conducting of the artificial aging heat treatment cycle is observed, namely: after six hours of holding, there was an "accidental stop" of 2 hours, after which the cycle was resumed, and after the period in that the material thermocouples (temperature sensors, recordings highlighted with different colours on the diagram) reached the holding temperature again, the cycle continued with 2 hours in the holding period (equal with the stopping period), in total, the holding time was equal to the period imposed in the recipe, namely 8 hours.

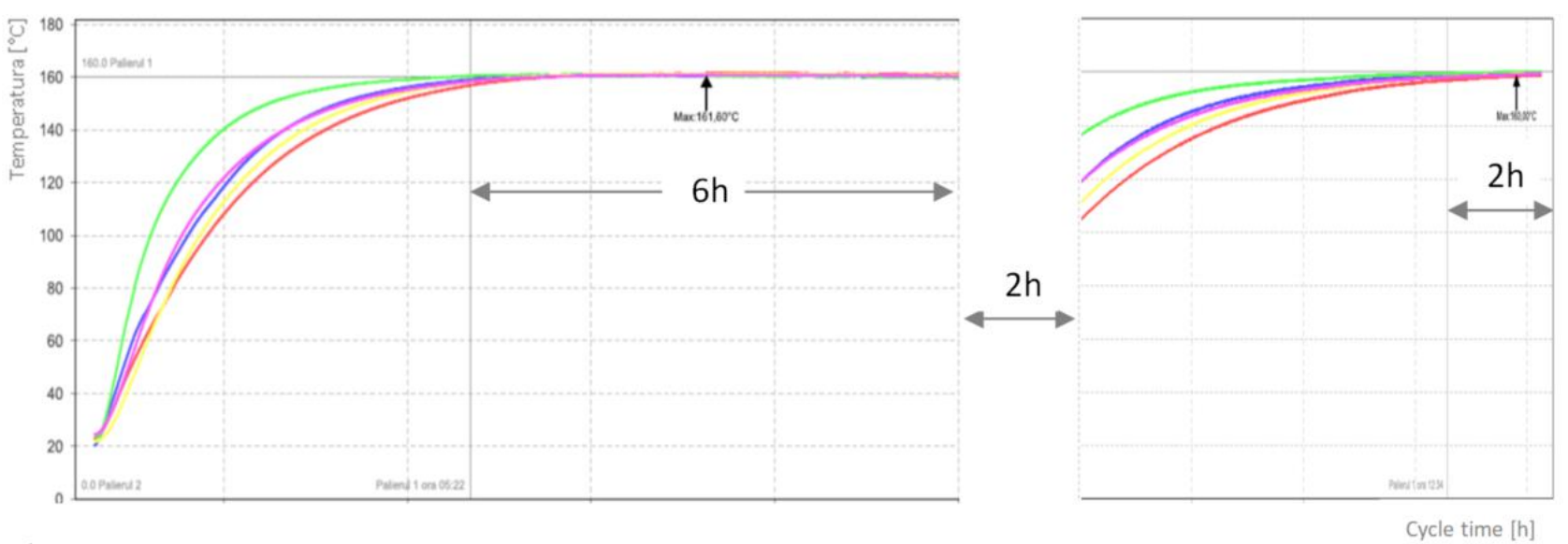

Fig. 6. Diagram for test batch subjected to the artificial aging heat treatment and simulation of "voltage drop in the holding period" 
RECENT, Vol. 22, no. 1(63), 2021

From the database of the Mechanical Testing Laboratory were extracted in Table 4 the values of the mechanical characteristics obtained for the 6061 thick plate type products treated in the test batch for which an "accidental" shutdown of the thermal equipment took place.

Table 4. Mechanical properties imposed and obtained on the products treated in the test batch - "voltage drop" during the holding period

\begin{tabular}{|c|l|c|c|c|c|c|c|}
\hline \multirow{2}{*}{ No. } & \multicolumn{1}{|c|}{$\begin{array}{c}\text { Dimensions } \\
{[\mathrm{mm}]}\end{array}$} & $\begin{array}{c}\text { Minimum imposed values } \\
{[\mathrm{Mpa}]}\end{array}$ & $\begin{array}{c}\mathrm{Rp} \\
{[\mathrm{Mpa}]}\end{array}$ & $\begin{array}{c}A \\
{[\%]}\end{array}$ & $\begin{array}{c}R m \\
{[\mathrm{Mpa}]}\end{array}$ & $\begin{array}{c}R p_{0.2} \\
{[\mathrm{Mpa}]}\end{array}$ & $\begin{array}{c}A_{50 \mathrm{~mm}} \\
{[\%]}\end{array}$ \\
\hline 1 & $8 \times 1520 \times 3020$ & 290 & 240 & 9 & 347 & 315 & 14.0 \\
\hline 2 & $38.1 \times 927.1 \times 2451.1$ & 290 & 240 & 8 & 332 & 303 & 11.5 \\
\hline 3 & $6.35 \times 1231.9 \times 3670.3$ & 290 & 240 & 9 & 328 & 279 & 19.0 \\
\hline 4 & $25.4 \times 2000 \times 4000$ & 290 & 240 & 9 & 334 & 299 & 15.5 \\
\hline 5 & $88.9 \times 2000 \times 4000$ & 290 & 240 & 5 & 342 & 313 & 11.5 \\
\hline 6 & $8 \times 1520 \times 3020$ & 290 & 240 & 9 & 345 & 307 & 15.5 \\
\hline 7 & $10 \times 1525 \times 3660$ & 290 & 240 & 9 & 332 & 296 & 16.5 \\
\hline 8 & $10 \times 1525 \times 3660$ & 290 & 240 & 9 & 335 & 286 & 20.0 \\
\hline 9 & $35 \times 1520 \times 3020$ & 290 & 240 & 8 & 334 & 302 & 13.0 \\
\hline 10 & $15 \times 1520 \times 3020$ & 290 & 240 & 8 & 336 & 301 & 14.5 \\
\hline 11 & $25.4 \times 1231.9 \times 3060.7$ & 290 & 240 & 8 & 344 & 316 & 13.0 \\
\hline 12 & $9.525 \times 1536.7 \times 3670.3$ & 290 & 240 & 9 & 349 & 312 & 16.5 \\
\hline 13 & $9.525 \times 1536.7 \times 3670.3$ & 290 & 240 & 9 & 347 & 306 & 16.5 \\
\hline 14 & $38.1 \times 1231.9 \times 2451.1$ & 290 & 240 & 8 & 347 & 312 & 13.5 \\
\hline 15 & $38.1 \times 1231.9 \times 3670.3$ & 290 & 240 & 8 & 343 & 308 & 13.5 \\
\hline
\end{tabular}

From the analysis of the results obtained for the mechanical properties of the products treated for artificial aging in the test batch in which a simulated shutdown took place, it is observed that all batches of 6061 alloy plates presented values above the minimum limits imposed in the reference norms.

\section{Conclusions}

Accidental shutdown of thermal equipment during the heat treatment cycle is an undesirable but possible situation. The present work aimed to provide practical solutions for products treated in batches where accidental shutdowns occurred, due to the influence of cycle interruption on the mechanical properties obtained from these products.

The moment during the cycle of artificial aging heat treatment in which an accidental stop can take place as well as the duration of this stop were simulated in the laboratory with samples taken from a 6061 aluminium alloy plate, samples which were then processed for tensile tests.

The results obtained in the laboratory were industrially validated on a test batch by a programmed interruption.

Any interruption in the heat treatment cycle caused a decrease in tensile strength. The maximum values for $R m$ (332 and $331 \mathrm{MPa}$ ) were obtained in the case of the reference cycle (without interruption) and for the cycle in which the interruption $(1 \mathrm{~h})$ took place during the heating period.

A value very close to the reference value for $R m$ was obtained if the stop was 1 hour during the holding period and this period was fully conducted ( 8 hours). The lowest value for $R m$ was obtained in the case of stopping for 2 hours during the holding period, without this period being added to the holding after starting; in this case, a value lower than the minimum value imposed in the norm was obtained for yield tensile strength (233 compared to $240 \mathrm{MPa}$ ).

The yield tensile strength presented a trend similar to the ultimate tensile strength. For the elongation at break, no dependence was identified on the moment and period of stopping the thermal equipment at the laboratory tests. 
From the tests performed it can be concluded that if the shutdown takes place during the heating period or during the holding period, but the break period is added to the restart, the mechanical properties are not decisively affected.

Future research will include the carrying out of certain analyses (metallographic, EDAX, etc.) because the precipitate size and the distribution pattern can be modified and this could influence the mechanical properties of the experiments described here.

\section{Acknowledgements}

Part of the cost of the industrial equipment used to obtain the results presented in this work was funded by European Union through Competitiveness Operational Programme, Research Priority Axis 1, Technological Development and Innovation, within the project "Investments in the R\&D Department of ALRO aiming at improving the research infrastructure for the aluminium alloy heat treated plates with high qualification industrial applications", based on the Funding Contract no. 42/05.09.2016.

\section{References}

1. Kumar M., Baloch M.M., Abro M.I., Memon S.A., Chandio A.D. (2019): Effect of Artificial Aging Temperature on Mechanical Properties of 6061 Aluminum Alloy. Mehran University Research Journal of Engineering and Technology, e-ISSN 2413-7219, Vol. 38, no. 1, pp. 31-36, https://doi.org/10.22581/muet1982.1901.03, https://publications.muet.edu.pk/index.php/muetrj/article/view/732/293

2. Zoller H., Ried A. (1971): Metallkundliche Gesichtspunkte bei der Entwicklung wenig abschreckempfindlicher AlMgSi-Legierungen (Metallurgical Aspects in Development of Al Mg Si Alloys with a Low Sensitivity to Quenching). Zeitschrift fuer Metallkunde (International Journal of Materials Research), ISSN 1862-5282, Vol. 62, no. 5, pp. 354-358, DOI: 10.1515/ijmr-1971-620503

3. Jastrzebski Z.D. (1987): The Nature and Properties of Engineering Materials. Wiley, 3 ${ }^{\text {rd }}$ edition, ISBN 9780471818410

4. Marioara C.D., Nordmark H., Anderson S.J., Holmestad R. (2006): Post- ${ }^{\prime \prime}$ phases and their influence on microstructure and hardness in 6xxx Al-Mg-Si alloys. Journal of Materials Science, ISSN 0022-2461, Vol. 41, pp. 471-478, DOI: $10.1007 /$ s10853-005-2470-1

5. Purushothaman R. (2008): Evaluation and Improvement of Heat Treatment Furnace Model. PhD thesis, https://web.wpi.edu/Pubs/ETD/Available/etd-082208-114851/unrestricted/Purushothaman.pdf

6. BS EN 485-2:2016+A1:2018 (2016): Aluminium and aluminium alloys. Sheet, strip and plate. Mechanical properties. https://shop.bsigroup.com/ProductDetail?pid=000000000030366788 